\title{
VHA PAIN RESEARCH WORKING GROUP AND VHA PAIN CARE
}

Rollin M. Gallagher, MD, MPH

T his important special issue of the Journal of Rehabilitation Research \& Development (JRRD) documents the steady progress of the Veterans Health Administration (VHA) in promoting and supporting pain research. As described by Drs. Kerns and Heapy in their Editorial [1], the development of the VHA's pain research enterprise has evolved over many years, with a particular focus on understanding the factors, including combined treatments, that affect the course and outcome of pain care for Veterans and inform clinical policy. The articles herein provide a sample of the breadth and sophistication of the VHA pain research enterprise in several domains: observational studies that help us understand the biopsychosocial factors influencing the development and perpetuation of chronic pain and pain treatment outcomes in Veterans with chronic pain and its comorbidities, such as posttraumatic stress disorder; investigations of the effects of exercise on pain sensitivity; and studies of the efficacy of multimodal treatments, e.g., combining exercise with medications to improve physical capacity.

An important nidus of the VHA's effort lies in the Pain Research Working Group (PRWG), led by Dr. Kerns, which has met by telephone monthly for many years and in face-to-face meetings in several venues. These meetings have served to enable dialog between officials from the VHA's Office of Research Development (ORD) with pain investigators, to introduce new investigators to the VHA pain research enterprise, and to foster collaborations among VHA investigators and research centers. Meetings of the PRWG in several retreats and, in recent years, at the yearly Health Services Research \& Development (HSR\&D) meetings have enabled the interpersonal connectivity so critical to social networking in the development of a multicenter research enterprise. As an example, the VHA Center for Healthcare Equity Research and Promotion based at my VHA institution, the Philadelphia Department of Veterans Affairs (VA) Medical Center, supported a PRWG retreat chaired by Dr. Kerns in 2005, when I was new to the VHA, that led to my connection to VHA's Rehabilitation Research \& Development Service (RR\&D) and my subsequent research, education, and policy work with the Department of Defense and with several VHA investigators. The RR\&D-sponsored pain state-of-the-art research conference in September 2007, focusing on Veterans of the wars in Iraq and Afghanistan and chaired by Dr. Kerns, led to a special issue on VHA pain research in Pain Medicine in 2009, co-edited by Dr. Kerns and pain research leader Dr. Steve Dobscha from Oregon [2].

Dr. Kerns' extraordinary leadership in encouraging, sustaining, and expanding VHA pain research over these many years, which has been strongly supported by Dr. Kusiak and VHA ORD as well as VHA Central Office leadership, has been accompanied by a steady growth in the pain research enterprise throughout VHA. A recent highlight is the HSR\&D-funded Center of Innovation (COIN) at the VA Connecticut Healthcare System, called the Pain Research, Informatics, Multi-Morbidities, and Education (PRIME) Center led by Drs. Kerns, Heapy, and others, which convenes research experts from around VHA to focus on pain research and complements other VHA centers that, although not exclusively devoted to pain research, have developed important pain research programs. Of particular note is research at the primary care level that has provided support for the Stepped Care Model [3-8]. Following the COIN award, Dr. Kerns' administrative leadership of the National VHA Pain Management Program Office naturally evolved to his present position as Special Advisor for Pain Research to our office, which involves his participation in our weekly pain management office 
meetings and frequent presentations by members of the PRWG. This regular communication conveys several key benefits to VHA pain research. It enables the perpetuation of a close working relationship between the PRWG and the National Pain Management Program Office in Central Office, ensuring that VHA pain research is informed by the clinical needs of our Veterans and the policy needs for their health services as well as effective partnerships between our office and investigators in the field.

VHA's pain research enterprise addresses our society's important need for implementation research, a recognized "donut hole" of the National Institutes of Health research portfolio. Our clinical and administrative database, built on the electronic health record, enables studies of larger trends in care, variability in care, and the effects of larger scale practice interventions and policy changes, as well as epidemiologic studies that inform hypotheses for prospective studies, clinical trials, and implementation research. Moreover, the need for translational research leading to effective biologic treatments with lesser toxicities that can be paired with neurobehavioral therapies has never been greater. The future is bright for VHA pain research.

\section{Rollin M. Gallagher, MD, MPH}

National Program Director for Pain Management, VHA; Clinical Professor, Psychiatry and Anesthesiology, University of Pennsylvania, Philadelphia, PA

Email: Rollin.Gallagher@va.gov; rollin.gallagher@ uphs.upenn.edu

\section{REFERENCES}

1. Kerns RD, Heapy AA. Advances in pain management for Veterans: Current status of research and future directions. J Rehabil Res Dev. 2016;53(1):vii-x. http://dx.doi.org/10.1682/JRRD.2015.10,0196

2. Kerns RD, Dobscha SK. Pain among veterans returning from deployment in Iraq and Afghanistan: Update on the Veterans Health Administration Pain Research Program. Pain Med. 2009;10(7):1161-64. [PMID:19818026] http://dx.doi.org/10.1111/j.1526-4637.2009.00722.x

3. Gallagher RM. Primary care and pain medicine. A community solution to the public health problem of chronic pain. Med Clin North Am. 1999;83(3):555-83.
[PMID:10386115]

http://dx.doi.org/10.1016/S0025-7125(05)70124-3

4. Wiedemer NL, Harden PS, Arndt IO, Gallagher RM. The opioid renewal clinic: A primary care, managed approach to opioid therapy in chronic pain patients at risk for substance abuse. Pain Med. 2007;8(7):573-84. [PMID:17883742]

http://dx.doi.org/10.1111/j.1526-4637.2006.00254.x

5. Dobscha SK, Corson K, Perrin NA, Hanson GC, Leibowitz RQ, Doak MN, Dickinson KC, Sullivan MD, Gerrity MS. Collaborative care for chronic pain in primary care: A cluster randomized trial. JAMA. 2009;301(12):1242-52.

[PMID:19318652]

http://dx.doi.org/10.1001/jama.2009.377

6. Kroenke K, Bair MJ, Damush TM, Wu J, Hoke S, Sutherland J, Tu W. Optimized antidepressant therapy and pain self-management in primary care patients with depression and musculoskeletal pain: A randomized controlled trial. JAMA. 2009;301(20):2099-2110.

[PMID:19470987]

http://dx.doi.org/10.1001/jama.2009.723

7. Gallagher RM. Chapter 89: Pain medicine and primary care: The evolution of a population-based approach to chronic pain as a public health problem. In: Deer TR, Leong MS, Buvanendran A, Gordin V, Kim PS, Panchal SJ, Ray AL, editors. Comprehensive treatment of chronic pain by medical, interventional, and behavioral approaches. The American Academy of Pain Medicine textbook on patient management. New York (NY): Springer; 2013. p. 1003-1100.

8. Bair MJ, Ang D, Wu J, Outcalt SD, Sargent C, Kempf C, Froman A, Schmid AA, Damush TM, Yu Z, Davis LW, Kroenke K. Evaluation of Stepped Care for Chronic Pain (ESCAPE) in Veterans of the Iraq and Afghanistan conflicts: A randomized clinical trial. JAMA Intern Med. 2015;175(5):682-89. [PMID:25751701] http://dx.doi.org/10.1001/jamainternmed.2015.97

This article and any supplementary material should be cited as follows:

Gallagher RM. VHA Pain Research Working Group and VHA pain care. J Rehabil Res Dev. 2016;53(1):xv-xvi. http://dx.doi.org/10.1682/JRRD.2015.10.0195

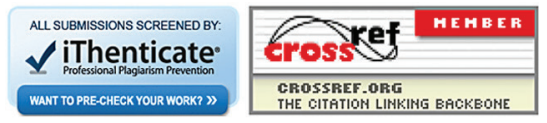

